\title{
Mediastenal Thymoma in a Young Female Diagnosed on FNAC: A Rare Case Report
}

\author{
Shivani $\mathbf{M}^{*}$, Sumiti G, Jyoti S, Renuka V, Ajay K and Rajeev S
}

Department of Pathology, PGIMS, Rohtak, Chandigarh, India

\begin{abstract}
Thymoma is a rare malignancy of unknown etiology. Thymoma is exceedingly uncommon in children and young adults. A cytologic diagnosis of thymoma is extremely challenging as the tumor is uncommon and aspirates are infrequently encountered. With this case report, we want to emphasize the importance of the fine needle aspiration cytology in the diagnosis of this rare neoplasm.
\end{abstract}

Keywords: Thymoma; Young; Female

\section{Introduction}

Thymoma is a rare tumor derived from thymus epithelial cells and occurs mostly in patients between 40 and 60 years old with slight male predominance. Thymomas account for less than $1 \%$ of the human neoplasms. They are rare in children and young adults [1]. Fine needle aspiration cytology of thymic epithelial neoplasms remains an underutilized method of sampling mediastinal masses. A cytologic diagnosis of thymoma is extremely challenging because the tumour is uncommon and aspirates are infrequently encountered. Moreover, a proper sampling with the help of a technically proficient interventional radiologist is needed for correct diagnosis. With this case report, we want to emphasize the importance of the fine needle aspiration cytology in the diagnosis of this rare neoplasm.

\section{Case Report}

A 15 years old girl came with the complaints of heaviness in the chest along with low grade fever with complaints of weakness, anorexia and weight loss. The chest $\mathrm{x}$-ray revealed mediastenal widening (Figure 1). CT scan of the chest revealed a mediastinal mass of size approximately $4 \times 4 \mathrm{~cm}$ and possibility of lymphoma was suggested. Patient was anaemic (haemoglobin: $7.5 \mathrm{~g} / \mathrm{dl}$ ) and had high sedimentation rate $(80 \mathrm{~mm} / \mathrm{h})$. Bone marrow aspiration and peripheral blood smear were normal. Urine analysis, routine serum biochemical tests as liver, kidney function tests and lipid profile were within normal limits. Alpha feto protein, beta-Human chorionic gonadotropin, and

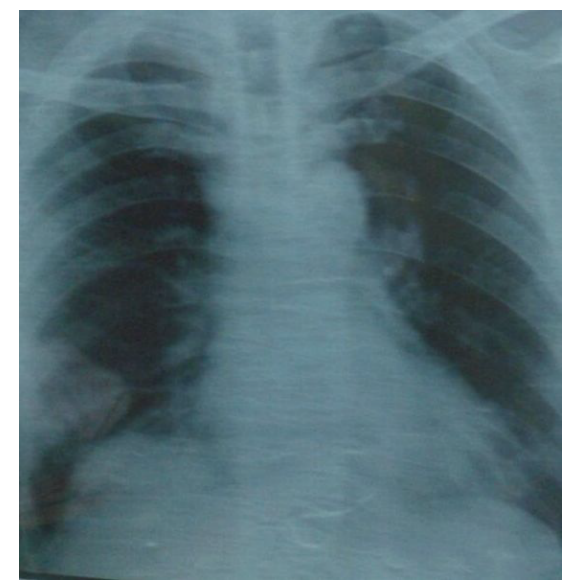

Figure 1: Chest X- Ray showing mediastenal widening.

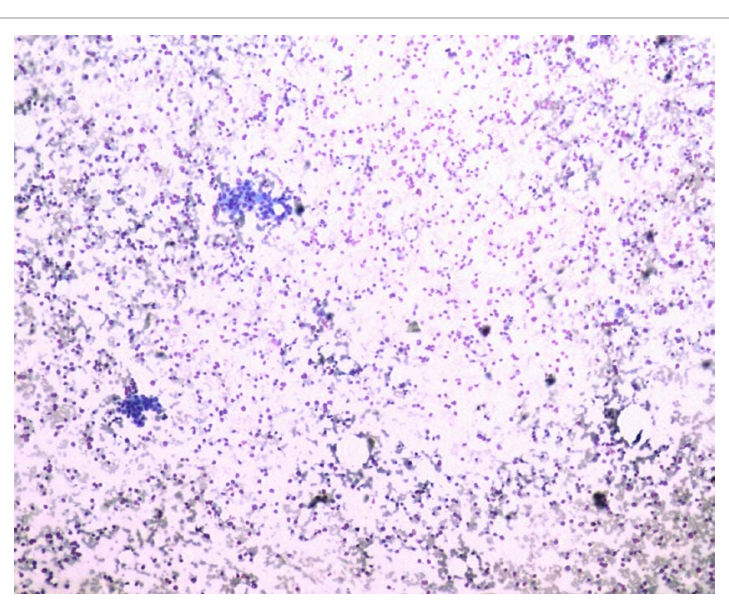

Figure 2: Clusters of bland epithelial cells in a background of lymphoid cells. 100X.

urine vanillylmandelic acid levels were normal which made us to rule out germ cell tumors and pheochromocytoma. The CT guided fine needle aspiration of the mass was done. FNA smears predominantly consisted of mature and immature lymphoid cells. Furthermore, clusters and groups of epithelial cells having round to oval nuclei, fine nuclear chromatin, inconspicuous nucleoli and moderate amount of pale basophilic cytoplasm (Figures 2 and 3) against a background of few tingible body macrophages and blood were seen. Based on the clear cut presence of aggregates of epithelial cells amongst the lymphoid cells, the diagnosis of thymoma was given. The diagnosis was confirmed on histopathology, supported by thymic epithelial cells positivity for cytokeratin.

\section{Discussion}

Thymoma is exceedingly uncommon in children and young adults,

*Corresponding author: Shivani Malik, Department of Pathology, Medical College, PGIMS, Rohtak, Chandigarh, India, Tel: 09992935860; E-mail: shivani.dr04@gmail.com

Received July 20, 2015; Accepted August 17, 2015; Published August 19, 2015.

Citation: Shivani M, Sumiti G, Jyoti S, Renuka V, Ajay K, et al. (2015) Mediastenal Thymoma in a Young Female Diagnosed on FNAC: A Rare Case Report. J Cytol Histol 6: 366. doi:10.4172/2157-7099.1000366

Copyright: @ 2015 Shivani M, et al. This is an open-access article distributed under the terms of the Creative Commons Attribution License, which permits unrestricted use, distribution, and reproduction in any medium, provided the original author and source are credited. 


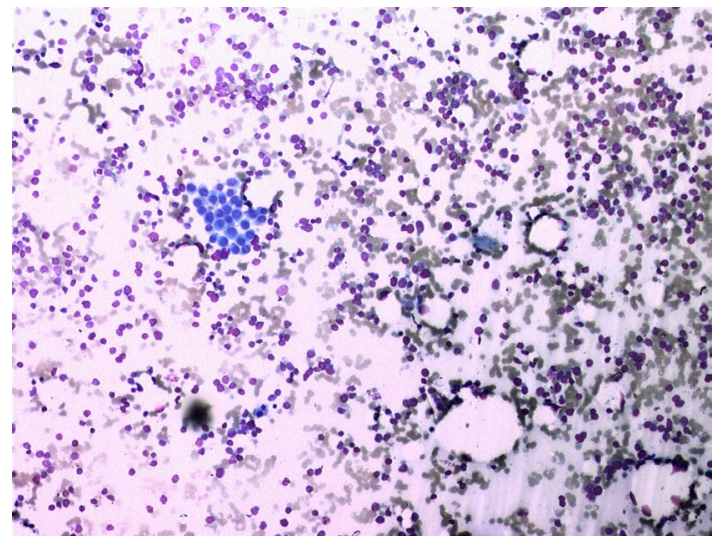

Figure 3: High power view showing a cluster of epithelial cells against a background of lymphoid cells. $200 \mathrm{X}$.

rises in incidence in middle age, and peaks in the seventh decade of life [2]. Thymomas have a variable presentation, manifesting either concurrently with myasthenia gravis, with local symptoms like chest pain, neck mass, superior vena cava syndrome or asymptomatically as a mediastinal mass on chest radiography [3]. A specific cytological diagnosis of thymoma is among the most difficult attempted in FNA cytopathology. In a well-performed FNA biopsy, the slides from a thymoma regardless of histologic subtype are moderately cellular or even hypercellular. The large number of lymphocytes found in these aspirates is a heterogeneous group with small round lymphocytes being most common and larger transformed lymphocytes constituting a smaller percentage. Critical to the cytologic diagnosis of thymoma is the recognition of a second distinct population of epithelial cells admixed with lymphocytes [4]. Epithelial cells in all forms of type B thymoma typically can exist in tightly clustered microfragments in which it can be difficult to appreciate individual cell morphology as was in our case. In our case, the groups of epithelial cells were widely scattered and cominggled with lymphocytes in such a way that on initial examination appeared to be those of a lymph node aspirate because of the overwhelming lymphoid population. However, close scruitiny of the smears led to the finding of groups and clusters of epithelial cells which turned the diagnosis in favour of a thymic neoplasm over lymphoma. Histologically, thymomas are divided into WHO Type A and Type $\mathrm{B}$ corresponding to spindle cell thymomas and lymphocyte rich or lymphocytic thymomas respectively [5]. Most thymomas fall into WHO Type B histologic subtype. Depending on histologic subtypes (WHO Type B1, B2, or B3), epithelial cells are present in differing amounts from being relatively inconspicuous and infrequent in smears (WHO Type B1) to being the predominant cell type (WHO Type B3). As it is not infrequent for there to be histopathologic transitions in thymoma (mixture of $\mathrm{B} 1, \mathrm{AB}, \mathrm{B} 2$, and $\mathrm{B} 3$ subtypes) even within the same mass, it would be imprudent to attempt this on FNAC that samples only a small fraction of the tumor [6]. Immunohistochemical application of cytokeratin on smears for epithelial cell demonstration may aid in the diagnosis and should be performed.

Differential diagnosis of thymoma most commonly constitutes lymphoid neoplasms like Non Hodgkins and hodgkins lymphoma. The abundant lymphoid population of WHO Types B1 and B2 thymoma can easily obscure epithelial cells creating the false impression of a lymphoproliferative neoplasm [7]. Epithelial cells are absent in both hodgkins and non-Hodgkin lymphoma but entrapped or adjacent thymic tissue may be aspirated to confound the cytologic picture, and erroneously diagnose a lymphoma as a thymoma. Furthermore, secondary lymphoid follicle formation may occur within thymoma especially in myasthenia gravis patients. FNA that samples only these structures will produce smears identical to those of reactive lymphoid tissue and in addition to a polymorphous population of lymphocytes, the presence of tingible-body macrophages, dendritic-lymphocytic aggregates and follicular center cell fragments are found [8]. Literature suggests that cystic change may occur in thymoma and in such a case a fluid aspirate may be obtained which is usually inadequate for diagnosis and sampling must be done from the solid part of the tumor. So, an adequate and proper radiologically assisted swelling is must for the proper diagnosis of thymoma. Fine-needle aspiration cytology plays a significant role in the diagnosis of anterior mediastinum masses, contributing to the early management and choice of the optimal therapeutic manipulation [9].

\section{Conclusion}

We must consider the possibility of thymic neoplasm in lymphoid cell rich aspirate from a mediastenal mass even in a young patient and attempt to find out any epithelial cell population. FNAC along with clinical and radiological findings renders a definitive diagnosis of thymoma and must be used as preliminary tool for early and appropriate intervention.

\section{References}

1. Pescarmona E, Giardini R, Brisigotti M, Callea E, Priscane A, et al. (1992) Thymoma in childhood:a clinicopathological study of five case. Histopatholgy 21: $65-68$.

2. Armitage $P$, Doll $R$ (1954) The age distribution of cancer and a multi-stage theory of carcinogenesis. Br J Cancer 8: 1-12.

3. Thomas CR, Wright CD, Loehrer PJ (1990) Thymoma: state of the art. J Clin Oncol 17: 2280-2289.

4. Dahlgren S, Sanstedt S, Sundstrom C (1983) Fine needle aspiration cytology of thymic tumors. Acta Cytol 27: 1-6.

5. Travis WD, Brambilla E, Muller-Hermelink HK (2004) World Health Organization Classification of Tumours. Pathology and Genetics of Tumours of the Lung, Pleura, Thymus and Heart. Lyon IARC Press.

6. Moran CA, Suster S (2000) On the histologic heterogeneity of thymic epithelia neoplasms. Impact of sampling in subtyping and classification of thymomas. Am J Clin Pathol 114: 760-766.

7. Ali SZ, Erozan YS (1998) Thymoma. Cytopathologic features and differential diagnosis on fine needle aspiration. Acta Cytol 42: 845-854.

8. Shin HJ, Katz RL (1998) Thymic neoplasia as represented by fine needle aspiration biopsy of anterior mediastinal masses. A practical approach to the differential diagnosis. Acta Cytol 42: 855-864.

9. Pantidou A, Kiziridou A, Antoniadis T, Tsilikas C, Destouni C, et al. (2006) Mediastinum Thymoma Diagnosed by FNA and Thin Prep Technique: A Case Report. Diagn Cytopathol 34: 37-40 